\title{
SOCIAL SCIENCE AS A PANACEA FOR CREATING A PEACEFUL WORLD: MYTH OR REALITY
}

\author{
Seema Agnihotri* \\ Amity Institute of Education, AUUP \\ Email:*seema.agnihotri@gmail.com
}

Social Science As a Panacea for Creating A Peaceful World: Myth or Reality

\begin{abstract}
The current century can be easily marked by dichotomies where on the one hand humanity is experiencing dense connectivity through advance technology and sweeping waves of globalization and on the other feeling isolated and alone at the individual level. Over emphasis on science and technology in the society as the panacea for all the problems have not only mitigated the image of the social sciences but also invited multiple troubles like terrorism, violence, intolerance, environmental degradation in an unprecedented manner. The subservient treatment of social sciences is diminishing the concern for sustaining the welfare of human being and environment through constructive and meaningful participation. With this background, this paper is attempting at the theoretical level with slight empirical evidences to inter relate social sciences for creating peaceful world. In order to vindicate the objective, data was collected from the secondary level students and pre-service teachers to know their perception for the social sciences as to what extent they are interested in pursuing for social sciences at the higher level. The paper concludes by evolving the framework where social sciences will be interlinked with the goal of creating the peaceful world.
\end{abstract}

Keywords: Science vs Social Sciences, prejudices, nature of social sciences, peaceful world

\section{Introduction}

Immediately after the two world wars and the liberation of the many countries of world from the stigma of as a colony, one need was felt unanimously by everybody i.e. the search for peace and creating the peaceful world. The establishment of the United nation is the glaring example in this regard. The United nation since its inception has worked tremendously to maintain, sustain and retain the peace at the global level for ensuring the survival of the humanity without any hindrance. For example, the following quote clearly reflecting the motive of the United Nation in building peace

(In a period of transition and accelerated change marked by the expression of intolerance, manifestations of racial and ethnic hatred, the upsurge of terrorism in all its forms and manifestations, discrimination, war and violence towards those regarded as 'other' and the growing disparities between rich and poor, at international and national levels alike, action strategies must aim both at ensuring fundamental freedoms, peace, human rights, and democracy and at promoting sustainable and equitable economic and social development all of which have an essential part to play in building a culture of peace. This calls for a transformation of the traditional styles "of educational action."UNESCO Integrated Framework of Action on Education for Peace, Human Rights and Democracy)

Human being since its evolution is struggling hard to ensure long term survival on Earth by combating the violent instinct through indoctrinating the mind with the rationale and practice of peace as a mandatory practice. Since ages, the concept of peace got wide acceptance in different cultures in different forms. The concept of 
peace has developed throughout history and has had many different connotations. The word originates from the Latin term 'pax'. The ancient Romans consider peace as 'absentia belli' which referred to a situation in which there was no war fought within the borders of the Roman Empire. Similarly in India the word 'Shanti', in Greek, the word 'irne', the Arabic word 'Sala'am' and the Hebrew 'Shalom', the Chinese 'Ping' are synonym of peace . Each of these words implies harmony and justice and absence of physical violence.

The starting point to understand peace is to look at the link between violence and conflict, as stated in the paradigm of violence. In the contemporary era, the prospects of violence and conflicts have accelerated in an unprecedented manner. With the growing technology, awareness, urbanization, globalization and materialism, the concept of peace is receiving more jerks than the other concepts. The pervasive impact of terrorism, existence of perennial conflict zones in the world and huge losses of live due to eruption of natural hazards of different forms are some of the examples, keeping the humanity on stake on a broader level. Similarly in the specific levels, poverty, hunger, unemployment, breaking of joint family system, increasing cases of suicides, depression and loneliness, exploitation, injustice, stereotypes, prejudices and sustaining inequalities are giving further jerks to the roots of peace on a very intensive scale. It is quite paradoxical that in this era of unprecedented advancement, humanity at both the levels -group and individual levels are feeling more in turmoil than tranquility of any sort.

Peace is conceptualized simply as an absence of war or, more precisely, as a temporary suspension of hostilities secured by military power (Funk, 2002.)

While reviewing the related literature in this regard, it has appeared that man is losing peace at three broad levels - inner level, social level and peace with nature. Peace is a participatory nonviolent process that aims to prevent any form of violence, embraces the respect of human rights and aids the maintenance of nonviolent human interaction. Within this manual this concept is called True Peace. True Peace is based on the three pillars of human rights, nonviolence and participation. Since peace is understood as a process which keeps violence out of human interaction, one has to understand the framework for this type of peace. Three dimensions determine the social reality of each individual - the self, the relation to others and the relation to the environment. As illustrated before, violence can be directed at the very same dimensions, at oneself, to others and at the environment. truly in the state of True Peace has to feature peace within these three dimensions: That is why a community to find peace within an individual, Social peace within society and Environmental peace within the environment.

With this brief background of peace, now the question arises that whether through social sciences teaching and learning, one can create the peaceful world? The work has been done in this regard clearly indicates the possibilities of achieving the same, but the dense probe in this regard raises doubts. On the superficial level, social sciences may appear as attractive enough to create the peaceful world because of its dealing with the human world, but on reality it is different. The subjects like geography, history, political science, sociology etc. due to their affiliation with the social sciences have not been able to garner as much support and appreciation as the subjects like physics, biology, chemistry have. Whether social sciences can create a peaceful world or not can be debated strongly where both sides are having substantial evidences to argue, but lets' start with myth factor i.e why the claim of social sciences to create the peaceful world appears like a myth .

\section{Myth}

The myth aspect related with social sciences can be understood in terms of

Its weightage in the academics

Research potential to create the peaceful world 
Objective treatment of the social world.

Success of social sciences in creating cohesive image of the social world

Let's try to understand each point in detail

\section{Weightage of social sciences in the Academic world-}

The answer to this question is negative because in general social sciences are subjected to poor perception regarding its relevance and utility. The non-utilitarian perspective is so much strong that it is not recommended for the bright students to study at the higher level. While highlighting the status of social sciences, national curriculum framework in it s position paper ' Teaching of Social Sciences in India' reflected

"The popular perception of social science is that it is a non-utility subject. As a result, low self esteem governs the classroom-transaction process, with both teachers and students feeling uninterested in comprehending its contents. From the initial stages of schooling, it is often suggested to students that the natural sciences are superior to the social sciences, and are the domain of 'bright' students. Therefore, there is need to emphasise that the social sciences are essential to provide social, cultural, and analytical skills required to adjust to an increasingly interdependent world, and to deal with political and economic realities."

The same feeling got echoed in other countries of South Asia where the status of social sciences is comparatively more dismal than in India.

Apart from a few centers of excellence, the social sciences are not regarded as having high social value and relevance in India, Pakistan and Bangladesh. With the exception of economics, wages in the other disciplines are relatively low. The demand for higher education in disciplines like history and political science is declining throughout the region, due to their limited career opportunities. Sociology, a relatively new discipline compared to the others, offers better opportunities thanks to NGO-sponsored research. ( Knowledge Divides, Background paper, Social sciences in South Asia, Krishna and Krishna)

These reflections regarding the status of social sciences are highlighting the poor perception prevailing among the masses in general. With this reality when one tries to juxtapose social sciences viz a viz for creating the peaceful world, then the myth factor seems to be more relevant than the reality. Until social sciences are not getting due recognition in the academic world with as much fervor as sciences, its emergence as a tool for creating peaceful world would always remains skeptical.

From the point of view of the practitioners also, social sciences carry very weak potential for the peaceful world because as already been stated that the social scientists are normally ill equipped in using the appropriate tools of discovering the social world. The date collected by the researcher in different span of time clearly reflected the ignorance of the socio- cultural facts among the school students as well as among the pre-service teachers respectively. The data collected from the 70 secondary level students in Delhi NCR provided the dismal condition of the social sciences where negligible percentage of students expressed desire to pursue social sciences at the higher level. Similarly the pre service teachers had social science background at the senior secondary level projected different subjects as dull, dry, factual and of no use. The findings got vindicated when the researcher during her doctorate study titled ' Mental Maps of the Children of the SAARC Countries: A Case Study of Secondary School Students' found the acute ignorance among the school going students at the secondary and senior secondary level about the geographical, political, economical and socio-cultural aspects of the SAARC Countries in a acute level. In this context, the challenges mentioned by Owen William T. (1997) as 'THE CHALLENGES OF TEACHING SOCIAL STUDIES METHODS TO PRESERVICE ELEMENTARY TEACHERS' seems relevant to be highlighted as 
- Challenge 1: Negative Past Experiences with Social Studies

- Challenge 2: Lack of Interest in Teaching Social Studies

- Challenge 3: Confusion over the nature of Social Studies

- Challenge 4: Conflicting/Conservative Sociological beliefs

- Challenge 5: Selecting What to Teach

- Challenge 6: Using a Concurrent Social Studies Field Experience

This status of social sciences is obviously weakening its stand to emerge as the powerful medium to envisage the peaceful world. Unless society would not show interest to know about itself in a serious manner, possibilities to create the peaceful world would be a myth only.

\section{Research Potential to create the peaceful world?}

Here the answer is also negative. Leaving aside the western world where comparatively social sciences are performing well, research conditions in the Asian condition is quite poor. In this context the description given by the knowledge divide document makes the whole thing clear

"Social science R\&D funding in South Asia is quite marginal compared to that for the science and technology fields. In India, social science R\&D funding is a mere $8 \%$ of that of science and technology in recent years. The 11th Five Year Plan (2007-2012) is committed to increasing the education budget by four times that of the 10th Plan, but it is still too early to assess the effects of this commitment on social science research.

While the Department of Science and Technology (DST) disposed of 5,720 million rupees for R\&D projects in 2005-06, the ICSSR total budget per year works out around 410 million rupees for social science research.6 Social science research is also relatively absent from the numerous reports and recommendations by the advisory National Knowledge Commission of India. A cursory look into this Commission's reports and recommendations shows a strong predilection for science and technology, as the only social sciences mentioned are management and education. Between 1999 and 2004 there was a relative stagnation in the ICSSR's number of fellowships: senior fellowships granted to faculties stagnated and doctoral fellowships increased only marginally. The total number of fellowships also remained very low: only 50 senior, 59 post-doctoral, 262 fulltime and 402 part-time PhD fellowships were granted. ' (Knowledge Divide,)

\section{Objective treatment of the Social World?}

Here also the answer is not yes. The inability of the social sciences to bring consensual agreement in generating uniform interpretations for the geographical, historical, political and economical realities have not only weaken its stand comparatively in the academic world but also minimized its potential to create the peaceful world. The multiple versions of the given phenomena backed by ideological stand and personal, social and cultural contexts elude the readers to develop accuracy and appreciation for the social world. In India, this is very much seen when with each ideological shift in the centre the apex body of the curriculum framing i.e National Council of Educational Research and training attempts to change its social sciences syllabus. The filtering of character, varied interpretations of the social events, perspectives for the 'others' creates so much gaps in the knowledge that no one controls to develop skewed perception for the social world. This skewed perception later on promotes restlessness and violence when an individual fails to reconcile between the theory and reality.

The multiple interpretations, lack of universal theories, uneven developments in the different branches of the discipline are another set of reasons which are putting question mark on the prospect of using social sciences for 
creating the peaceful world. While perfect realization of such objectivity is not easy to achieve even in natural sciences, it is much more difficult to attain in social sciences. Unlike the natural scientists who generally do not have subjective reactions to the phenomenon they study and can easily abandon any preconceptions they hold about it, the social scientists are part of different social groups, communities, countries and cultures from which they inherit, derive and inculcate specific attitudes, biases, and prejudices. Burdened with this social and cultural baggage, and limited by their subjective reactions to some of the questions they study, they cannot pursue truth with the same degree of objectivity, notwithstanding the level of perfection of their methodology, as the natural scientists can do. These inherent constraints creates problem in viewing the social reality in its correct form. In India, with each political ideological shift, the changes in narratives by the social scientists for a particular phenomena within geographical, political and economical field in general and history in particular at the school level unable the recipients to establish accurate cause and effect relationship for the groups, societies or cultures.

\section{Success of Social Sciences in generating holistic cohesive image for the social world?}

It has also been seen that social scientists are carrying divisive knowledge and normally failed to project holistic perception for social sciences. If looking closely ,then it is quite apparent that history, geography ,political sciences, psychology, sociology, economics etc. are interrelated with each other in building up the causations of action in a particular social groups followed by structuring its existing form. The isolated treatment leaves behind several gaps in developing critical perception about the behavior of different groups in different parts of the world. In order to create the peaceful world, social sciences have to reshape it in building holistic perception for the human group.

\section{Reality}

But shall we lose hope and allowing the world to walk towards the violence, intolerance, hostilities and stereotypes? The answer must be no because we have covered a long journey of civilization to reach to the state of the art form and we are still aspiring for improvement. The unbridled usages and recognition of the sciences and mathematics have left the social sciences very much behind. The artificial intelligence, adaptive learning, surrogacy, test tube babies, smart phones, cloning, internet etc. have transformed the basic structure of social life in many countries of the world and India is not the exception. The ancient old civilization is now standing at the cross road and moving to cover the rest of the journey with the help of the science, technology, foreign language, western model of education, breaking the joint family system, promoting urbanization and inserting the philosophy of materialistic life. All these changes are eluding the young generation about the availability of the finite resources of the earth. The growing dependence on technology has removed the concern for the others, immediately available in the neighborhood, but causing to worry for those who are far away from home. Inside the home, parents and children are hardly having talking terms. Parents are wasting their money on their kids without providing any solid value system. That might be the reason that with increasing time children are reducing the definition of stress for the petty things and prefer to end their life in the absence of all these. The increasing rates of divorce, extra marital affairs, single parentings are enhancing the susceptibility of disintegration at both the individual as well as at the group level. The science and technology are promoting the greed and lead for the callous uses of the resources. These descriptions reflect that survival of the human being cannot be ensured with the scientific and technological development only. Along with that it is also vital to do hard work in evolving social theories through various disciplines of social sciences so that the growth of the humanity can be continued without any disruption. One has to make a start from somewhere and the good point is to start from children who through proper monitored environment can emerge as the mediator of the peaceful world. For this one has to insert deliberately certain components in the system which may cause at the broader level to appreciate peace as an inherent value. The problem is that education system in general is reeling under its own problems of stereotypes, prejudices, apathetic attitude in one way or the other. In order to minimize them, because eradication is impossible, social sciences can play a big role . 
Now to have the real use of social sciences for the peaceful world, broad scale transformations are required in the realm of knowledge offered in different institutions of the world. Due to our biases for the different types of knowledge, we have not been successful in converting the education in general and social sciences in particular as a major tool of creating a safe, secure and peaceful world. In order to do so following measures are required

Holistic Perception For Knowledge - It is very significant that except two categories i.e. of knowledge giver and knowledge takers, no other category should be endorsed. The very perception that only scientists are beneficial for the society and the social scientists are liability, should be removed on the priority basis. Instead, multidisciplinary approach should be given more thrust so that learners can balance themselves regarding the different versions of knowledge and use them properly. For example, currently major population in different countries of the world is obsessed with the mobiles and internet so much so that life seems to be incomplete without it. Right from home to school or college, teachers and students, both are addicted. Due to it, quality teaching and quality learning is diluting its rigour. At home also, parents and children both are busy in replying what's an App or face book message. It is depriving them to do any substantial investment in the social interaction. The market after observing this craze is taking benefit of this craze of the people and launching everyday some or the other tempting offers. The people get lured to it. Ideally there is hardly any deliberation has started to use the technology in the rational manner. The conversion of obsession into realistic and meaningful use has not been incorporated in the education. Alike examples are in abundance where people are going for it without seeing it social, cultural implications. Therefore the scientific and technological innovations should be properly balanced by the social sciences interventions by making the learners aware about it future implications. The unchecked growth of the sciences and technology and the subservient status of the social sciences is hampering the prospect of sustainable continuation of the humanity for a long period of time.

The cultivation of Social Science Attitude - For a long time, we know only about the cultivation of the scientific attitude by becoming the keen observer of the physical phenomena. But anything like social science attitude has never been demanded so vehemently. It might be the reason that with increasing intrusion of sciences and technology, the analytical power for the social phenomena is not prevalent strongly in any discourse of life. As a member of a particular society, everybody is feeling change, fear for the pace of changes and apprehension for the continuation of the changes, but along with this also feeling helpless that how to adapt oneself and the progeny to adapt with these changes in a meaningful manner. This concern is more popular in the Asian and African countries which under the pervasive wave of globalization are loosening their huge treasure of linguistic culture repositories as well as the core traits of particular socio-cultural milieu by accepting the western model as the role model to emulate. The dominant role of youngsters over the adults due to their proficiency in using the technology is not only reversing the biological relationship but also causing threat for the survival of the humanity. The depletion of the environmental and socio-cultural resources available in a particular set up under the geographical, historical, socio-psychological, political and economic reasons are developing strong sense of alienation. This alienation might be responsible for the growing violence, conflicts and insensitivities for the others. These problems are piling up because of the lack of social science perspective among the recipients. Along with the scientific journey, social sciences should also have to address these issues and should prepare the learners to maintain their self identity emanating from a citizen of a particular country, bounded by geographical peculiarities and shaped by series of historical events. For creating the peaceful world, social sciences should strive uniformly through their content delivery in the form of geography, history, political sciences, sociology etc. all across the world to enable the learners to develop critical perspective about different socio-cultural patterns available in the world in the reference of their geographical, sociological and political specificities. This critical perspective development expects the cultivation of the social science attitude which may cause to observe the social phenomena as keen observer. The encouragement to promote the scientific attitude has somewhere causing the humanity to be indifferent for its own problems and issues.

Correlation between Theory and Practical- Social science teaching and learning should be replete with case studies, simulations, field trips, excursion so that the relevance of the content can be highlighted immediately. In 
India, while observing social science teaching among pre-service teachers, it has been found that they are simply providing the text book knowledge without extending to the current examples. The relation of theory and practical will orient them to develop multiple perspectives in dealing with the social world and reduce the gaps to accommodate the 'others' in their mental schema.

Culturally Responsive Teaching -. According to Vavrus ' CRT is a student-centered strategy that embraces a learning community model for the organization of a classroom. CRT incorporates into classroom teaching and school policies and practices the cultural knowledge and assets of historically marginalized students and their communities and families. This approach rests on an equity pedagogy designed to rectify educational conditions that have fallen short of facilitating the learning of many students from racially, culturally, and economically diverse groups. As an educational reform, CRT represents a growing shift away from equating student "seat time" in a classroom with learning and to evaluating teacher performance on the basis of student engagement and gains in academic learning.' (Vavrus, M., Culturally Responsive Teaching) The adequate use of the culturally responsive teaching enables the learners to understand the vast domain of knowledge as per the available frames of reference in a given cultural milieu. The absence of culturally specific examples in the classroom for teaching different subjects creates an alienation which later on develops detachment for appreciating the peaceful world.

\section{‘ A Strategies by Albert (2003)}

\begin{tabular}{|l|l|}
\hline Acceptance & $\begin{array}{l}\text { Accepting students' cultural differences, accepting students with } \\
\text { disabilities, accepting students' personal life, accepting the Doer (active } \\
\text { person) not the Deed (action) }\end{array}$ \\
\hline Attention & $\begin{array}{l}\text { Providing a large dose of teachers' attention is very important. Also } \\
\text { teach students that asking for attention is a good strategy to avoid } \\
\text { misbehavior. }\end{array}$ \\
\hline Appreciation & $\begin{array}{l}\text { Using a three-part appreciation statement-- describes the student's } \\
\text { action, describes how teachers feel about action, and describes the } \\
\text { action's positive affect. }\end{array}$ \\
\hline Affirmation & $\begin{array}{l}\text { Affirmation statements verbally or in a written form encourage } \\
\text { students to believe in their known desirable traits and to become aware } \\
\text { of hidden traits }\end{array}$ \\
\hline Affection & $\begin{array}{l}\text { It is a powerful tool to express the teacher's attitude toward the } \\
\text { students. Good teachers are those who can not only present } \\
\text { information in a coherent, intelligent manner but also establish } \\
\text { mutually affectionate and rewarding relationships with their students. }\end{array}$ \\
\hline
\end{tabular}

The 'A' chart developed by Albert is encompassing all the basic components required for creating conducive environment for appreciating the peace. (Albert, 2003, p.121).

It is worth concluding that social sciences basically carries tremendous potential to reshape the human world into constructive and critical form where understanding for the 'others' falling into whatsoever category can prolong the survival for a long time. The better understanding of geography, history, political situations of different countries primarily followed by economics, sociology and psychology may cause to minimize the prejudice and discriminatory behavior. The ignorance of the human being in multiple contexts has accentuated the violence, conflict and ruthless behavior. The technological and scientific development in the absence of knowledge about human contexts though appears attractive at first sight but in the long run it is creating that world where we ourselves will be responsible for our own destruction. The current genetic mutations stored for centuries without alterations are leading us for that world where the concept of sustainable development in its reality and theory carries huge rift. 
'If we are to have peace on earth...our loyalties must transcend our race, our tribe, our class and our nation; and this means we must develop a world perspective.' ( Martin Luther King)

\section{References}

Agnihotri,S, 5(6): 911-917, 2017, Critical Reflection on the role of education as a catalyst of peace-building and peaceful coexistence, Universal Journal of Horizontal Research, http://www.hrpub.org.

Agnihotri,S et.el,2011, The Study of Mental Maps on Indian Children in Secondary Schools,ISBN-13 9783845421346,2011

boutellier_2011.pdf, $\quad$ accessed at $\quad$ 11.34AM $\quad$ on $\quad$ a/16/2017, www.collier.sts.vt.edu/sciwrite/pdfs/boutellier_2011.pdf

Curriculum_Guidelines_SocialStudies_Teaching_and_Learning.pdf, accessed at 4.15PM on 3/1/2015, https://www.socialstudies.org/.../Curriculum_Guidelines_SocialStudies_Teaching_and.

CulturallyResponsiveTeaching.pdf, accessed at $\quad$ 5.35PM $\quad$ on $2 / 2017$, https://static1.squarespace.com/static/.../t/.../CulturallyResponsiveTeaching.pdf

EdPractices_23.pdf, accessed at $\quad$ 6.10PM $\quad$ on $\quad 3 / 14 / 15$, www.ibe.unesco.org/fileadmin/user_upload/Publications/.../EdPractices_23.pd

Global citizenship.pdf,accessed at $\quad 11.51 \mathrm{AM} \quad$ on $\quad 1 / 17 / 2016$, https://depts.washington.edu/gcp/pdf/globalcitizenship.pdf

Hashmi-edited-book-SSB-full document-final.pdf, accessed at $12.28 \mathrm{PM} \quad$ o 1/26/2016, www.cosspak.org/publications.php?id=8

LERU_Geistes-und_Sozialwissenschaften_Statement.pdf, accessed at 5.45 PM on 6/4/2017, https://www.pr.unifreiburg.de/pm/2014/leiden-statemen

Nnamdi Azikiwe et el ,2014, SOCIAL STUDIES AS AN INSTRUMENT FOR GLOBAL PEACE: ANALYTICAL AND PRESCRIPTIVE PERSPECTIVES, Review of Public Administration and Management Vol. 3, No. 5, ISSN: 2315-7844

Peace Education Curriculum in U.S. and Geo.pdf , accessed at 1.15PM on 9/2/2017, www.pedocs.de/volltexte/2011/1511/pdf/handbook_on_peace_education_D_A.pdf

social studies for peace promotion.pdf,accessed at 11.54AM on 4/23/2017, unesdoc.unesco.org/images/0012/001252/125228eo.pdf

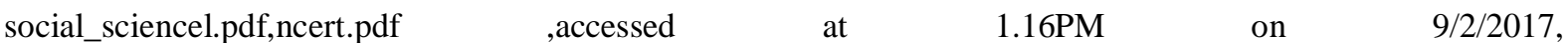
www.ncert.nic.in/departments/nie/dess/.../prin.../ITPD\%20Final\%20june\%2014.pdf

Z5229Y.pdf three cultures.pdf, accessed at 11.35AM on 9/16/2017, www.thedivineconspiracy.org/Z5229Y.pdf world social sci. report 2010.pdf,accessed at 11.30AM on 2/20/2016, unesdoc.unesco.org/images/0018/001883/188333e.pdf 